\title{
Biomechanical study of the Spider Crab as inspiration for the development of a biomimetic robot
}

\author{
Rita Rynkevic $^{1 \mathrm{a}}$, Manuel F. Silva*2 and M. Arcelina Marques ${ }^{1 \mathrm{~b}}$ \\ ${ }^{1}$ Physics Department, School of Engineering - Polytechnic of Porto, Rua Dr. António Bernardino de Almeida, \\ 4200-072 Porto, Portugal \\ ${ }^{2}$ INESC TEC - INESC Technology and Science (formerly INESC Porto) and ISEPIIPP - School of \\ Engineering, Polytechnic Institute of Porto, Rua Dr. António Bernardino de Almeida, \\ 4200-072 Porto, Portugal
}

(Received April 4, 2015, Revised August 14, 2015, Accepted September 15, 2015)

\begin{abstract}
A problem faced by oil companies is the maintenance of the location register of pipelines that cross the surf zone, the regular survey of their location, and also their inspection. A survey of the state of art did not allow identifying operating systems capable of executing such tasks. Commercial technologies available on the market also do not address this problem and/or do not satisfy the presented requirements. A possible solution is to use robotic systems which have the ability to walk on the shore and in the surf zone, subject to existing currents and ripples, and being able to withstand these ambient conditions. In this sense, the authors propose the development of a spider crab biologically inspired robot to achieve those tasks. Based on these ideas, this work presents a biomechanical study of the spider crab, its modeling and simulation using the SimMechanics toolbox of Matlab/Simulink, which is the first phase of this more vast project. Results show a robot model that is moving in an "animal like" manner, the locomotion, the algorithm presented in this paper allows the crab to walk sideways, in the desired direction.
\end{abstract}

Keywords: biomechanics; bioinspired robotics Spider Crab; modeling; simulation; SimMechanics

\section{Introduction}

There are a large number of pipelines extended into the seabed, a lot of them ending up in onshore pipelines, crossing the coastline. In this area of the route, pipelines are subject to extreme conditions, due to the high dynamics that the morphology of the seabed is subjected. Normally the pipelines traverse this zone buried, mainly in shallows.

The maintenance of an exact register of the location of the various pipelines that cross the surf zone is a task that must be solved by oil companies, which must regularly survey the location of pipelines, as well as inspect them in an automatic or semi-automatic way. However, the "complexity" of the seabed in the surf zone, which is subject to frequent changes in the bottom due

*Corresponding author, Professor, E-mail: mss@isep.ipp.pt

${ }^{a}$ MSc., E-mail: r.rynkevic@gmail.com

${ }^{\mathrm{b}}$ Professor, E-mail: mmr@isep.ipp.pt 
to motion and entrainment of inert, over time, involves changes of the ducts location (at least relative to the surface). Moreover, products that were initially resting on the seabed may, over time, remain located in sediments.

In addition to these factors, heterogeneous environments (different types of seabed, the effects of ocean currents, tides and swell) hinder the monitoring methodology development, either due to the difficulties to find a solution for vehicles locomotion which might be used in this application, or the difficulty of selecting the most appropriate sensory techniques.

The solution to the problem should allow to:

- find the location, georeference (in terms of $x, y, z$ coordinates) and to simulate the buried pipelines crossing the surf zone;

- inspect from the shore approach to the low tide line (depending on tidal range);

- inspect the range between the low tide line and high tide line (surf zone).

To define requirements for the task, it should be understood that the shore approach area is between $20 \mathrm{~m}$ to $3 \mathrm{~m}$ of depths and the surf zone lies between the coordinates of $3 \mathrm{~m}$ depth to the quota of high tide +1 meter (depends on the latitude of the area of operation).

To overcome this problem, the authors propose the development of a robotic system, which is capable of locomotion on the shore approach area and in the surf zone, subject to the existing currents and ripples, and able to withstand these ambient conditions, paying attention to:

- the robot body, with particular attention to its geometry (possibly bio-inspired), which provides a reduced hydrodynamic resistance;

- the locomotion system, able to move on the seashore as well as in sandy and rocky bottoms, overcoming the obstacles in its path;

- the sensors, suitable for ducts detection (the sensors should be located on board of the vehicle, which is mentioned in the preceding paragraphs).

From another perspective, in recent years significant advances have been made in creating bioinspired machines (Lepora et al. 2013). Scientists and engineers use animal characteristics to achieve these goals, as even the most advanced robots are much inferior to their biological counterparts. Animal locomotion is much more versatile, efficient and elegant and, therefore, it is reasonable to consider studying biological systems in order to apply their schemes in the design and control of mechanical robots (Xiaodong and Shusheng 2012). For these reasons, there has been an investment in the development of mechatronic mimic of varied animals such as the cricket (Birch et al, 2000), the chicken (Mederreg et al. 2003), the gorilla (Davis et al. 2003, Fukuda et al. 2012), the dog (Peng et al. 2003), the Hermann Turtle (Hennion et al. 2005) and the lobster (Ayers and Witting 2000).

In order to develop a walking robot able to move on the seashore, as well as in sandy and rocky bottoms, it was decided to study animals which present good locomotion abilities in these terrains. The spider crab became a good choice for inspiration among the different animals, due to its living environment (that fits with the purpose of the intended study) and also since the shape of the body and its structure can be envisaged as an approach to solve the stated problem. Based on these ideas, this study describes the biomechanical simulation developed for the spider crab.

This paper is organized as follows. Section two presents a brief description of the state of art on the previously stated subjects; section three is a brief summary about the spider crab, its anatomy and habits, with the determination of its biometric indices in section four. Sections five and six present the kinematic and the dynamic models, respectively. Section seven presents some simulation results obtained with the implemented model. Finally, section eight presents the main conclusions of this study and some ideas for future developments. 


\section{State of the art}

Following the problem that was identified, a survey on the state of art regarding the monitoring and locomotion in the surf zone was conducted and one could not find in literature robots capable to carry out the inspection of underwater pipelines in these conditions and in shallow depths, verifying that there is an opportunity for $\mathrm{R} \& \mathrm{D}$ in this area. Commercial technologies available on the market (Commercially available Off-The-Shelf - COTS) do not consider this particular problem and unsatisfactorily fulfill the requirements presented above. Moreover, from this same analysis of the state of art, it is apparent that the inspection area going from $3 \mathrm{~m}$ depth and approximately $3 \mathrm{~m}$ height above mean sea level (which can be considered the surf zone) is a scientific and technological challenge that should be encompassed.

Studying the biological creatures that live and move in the surf zone, according to the currents and swell, and without having mobility problems is the first step in biomimetics. From studied animals, those that showed the greatest potential to serve as a biologically inspired robot for the given task were: $(i)$ the spider crab (World register of marine species, 2014), shown in Fig. 1(a), which has good capabilities to move in the surf zone and on rocky ground; (ii) the horseshoe crab (Shuster 1982), shown in Fig. 1(b), that has good capacity for locomotion in the surf zone and sandy bottoms; and (iii) the sea turtle (Lutz et al. 2002), shown in Fig. 1(c), as the horseshoe crab has good mobility to move in the surf zone and sandy bottoms.

Concerning the aspect related to the development of a solution to the robots body, with biological inspiration, there are several vehicles for submerged locomotion, which typically have a fusiform shape.

Regarding the second aspect above, related to a solution of locomotion suitable to the beach/ocean bottom, from the reviewed literature, three forms of locomotion were found, which could be promising for this situation: (i) locomotion using whegs type appendages, as found in robot Rhex (Kevin et al. 2010) (Fig. 2(a)), (ii) locomotion using appendages like fins, such as found in the robot Aqua (Dudek et al. 2007) (Fig. 2(b)), (iii) and locomotion using worm screws, as can be seen in the vehicle CBOR ROV (Cbor pipe inspection rov, 2014) (Fig. 2(c)). Another research direction, that was reviewed and considered, was related to robotic vehicles for celestial bodies' exploration. Typically the environment found by these vehicles is highly unstructured and these have wheels (or more specifically appendages, intended for locomotion) with varied shapes that exhibit good mobility capacity and transposition to overcoming obstacles in different types of terrain (Sutoh et al. 2012, Issa et al. 2012).

Considering the above analysis, the spider crab was chosen as the target for further studies.

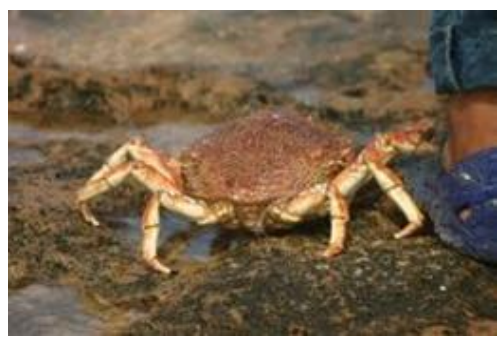

(a)

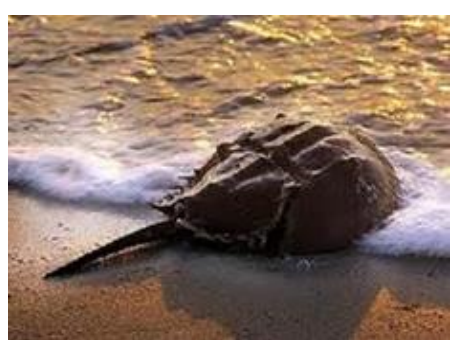

(b)

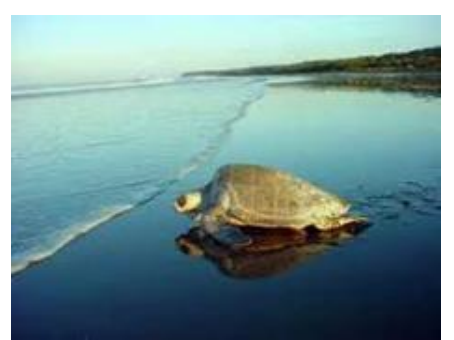

(c)

Fig. 1 Animals with good adaptation to the marine surf zone 


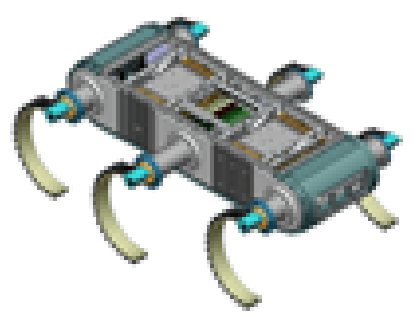

(a)

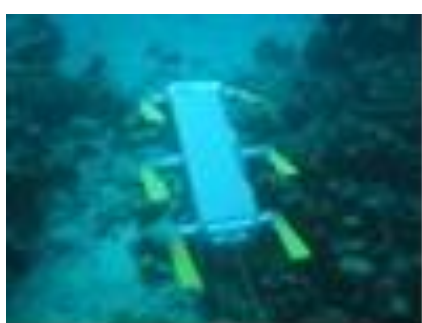

(b)

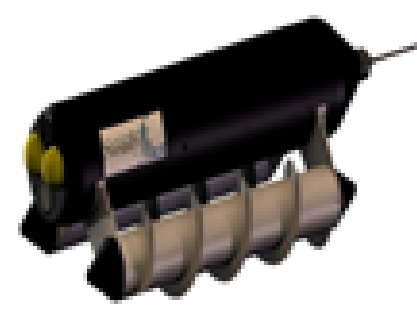

(c)

Fig. 2 Locomotion adopted by different types of robots

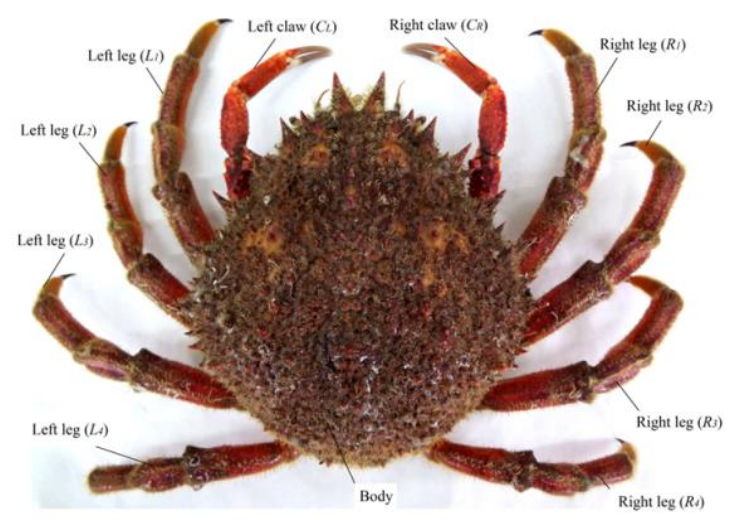

Fig. 3 Photo of Maja brachydactyla with the legs numbered according to the nomenclature used on this work

These studies are focused on the spider crab locomotion and, in a second phase, in its resistance to environment.

To study the spider crab locomotion, it was decided to develop a model in SimMechanics. This software has already been used previously in robot modeling, namely hexapod robots (Asif and Iqbal 2010) and parallel robots (Dan Stan 2008), being considered as simple, intuitive and accurate, by some authors (Shaoqiang et al. 2008).

Furthermore, the modeling process based on SimMechanics does not imply the computation of forward dynamics and differential equations, which are quite cumbersome and error prone, which makes it ideally suited for rapid virtual robot prototyping (Dede and Tosunoglu 2006).

\section{Spider crab (Maja brachydactyla)}

Maja brachydactyla (Fig. 3) (the European spider crab, spiny spider crab), a kind of edible crab belonging to the family Majidae arthropod decapod, is a species of migratory crab, which is found in the north-east Atlantic and the Mediterranean Sea. Maja brachydactyla also supports commercial fisheries in northern Spain (Galicia), Portugal and in the Adriatic Sea (The european spider crab biology and fishery, 2014).

This crab's carapace has a cord form and an irregular surface (with many nozzles), in general coated with algae, six spines on the longer side edges and two divergent large spikes in the front. It 
has five pairs of legs, two of which are strong clamps. Usually crabs live in sandy and rocky bottoms, where they hide among vegetation or in cracks. It feeds on algae, mollusks and echinoderms (The european spider crab biology and fishery, 2014). The spines are a protection against predators, but can also be dangerous for the unwary swimmers, if a carapace is trodden on. Fortunately they are not poisonous like some other organisms, such as the spider fish.

\section{Determination of biometric indices}

Biometry is the study, measurement and comparison of linear dimensions and other physical characteristics of the animal bodies. Some of the measured characteristics are: body mass, length, width and thickness.

Measurements of the crabs were made in Estação Litoral da Aguda (ELA), where four spider crabs (two of them were dead and two alive) were used. Their overall dimensions are summarized in Table 1.

Measuring the body, legs and other parts of the crab was made using a scale, a protractor and a micrometer. Fig. 4 shows a photo of left legs of one of the Maja brachydactyla crabs cut into segments.

Length and weight of each segment of the legs from the left and right sides were determined, and average indices were consequently calculated, as can be seen in Table 2 .

\subsection{Locomotion of Maja brachydactyla}

This sub-section deals with the biomechanics of walking and locomotion. Walking is an automatic motor action which occurs as a result of complex coordinated activity of the skeletal muscles of the trunk and extremities. The motion of the individual units of the free leg is determined not only by muscle contraction, but also by inertia. The crab's locomotion mode was determined establishing a chronogram.

Table 1 Metrics of the crabs

\begin{tabular}{ccccc}
\hline \hline Spider crab & Mass of the body $(M)$ & $\begin{array}{c}\text { Length of the } \\
\text { body }(L)\end{array}$ & $\begin{array}{c}\text { Width of the } \\
\text { body }(W)\end{array}$ & $\begin{array}{c}\text { Thickness of the } \\
\text { body }(T)\end{array}$ \\
\hline First specimen & $526.7 \mathrm{~g}$ & $142 \mathrm{~mm}$ & $117 \mathrm{~mm}$ & $58 \mathrm{~mm}$ \\
Second specimen & $891.0 \mathrm{~g}$ & $160 \mathrm{~mm}$ & $133 \mathrm{~mm}$ & $80 \mathrm{~mm}$ \\
\hline
\end{tabular}

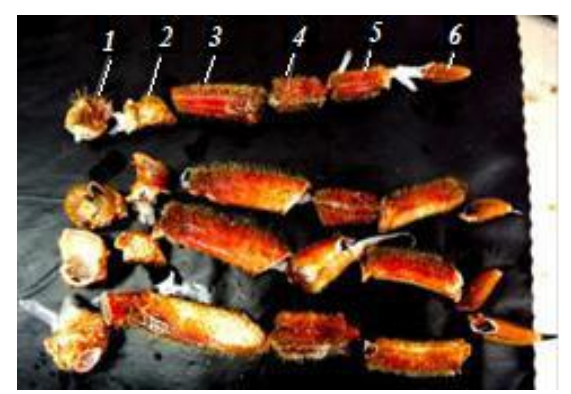

Fig. 4 Legs of Maja brachydactyla, cut in the respective segments 
Table 2 Average of the leg characteristic values of the first specimen

\begin{tabular}{|c|c|c|c|c|c|c|}
\hline $\begin{array}{c}\text { Leg } \\
\text { Number }\end{array}$ & $\begin{array}{c}\text { Segments o } \\
\operatorname{leg} n\end{array}$ & $\begin{array}{c}\text { Movement of } \\
\mathrm{f} \text { the leg between } \\
\text { joints around } \\
\text { axis: }\end{array}$ & $\begin{array}{c}\text { Amplitude of } \\
\text { movement } \\
\text { between joints } \alpha \\
\left({ }^{\circ}\right)\end{array}$ & $\begin{array}{l}\text { Length of the } \\
\text { segment } \boldsymbol{l}_{\boldsymbol{x}} \\
(\mathrm{mm})\end{array}$ & $\begin{array}{l}\text { Diameter of the } \\
\text { segment } \boldsymbol{d}_{\boldsymbol{x}} \\
(\mathrm{mm})\end{array}$ & $\begin{array}{c}\text { Mass of the } \\
\text { segment } \boldsymbol{m}_{\boldsymbol{x}}(\mathrm{g})\end{array}$ \\
\hline \multirow{6}{*}{ left leg $\boldsymbol{L}_{\mathbf{4}}$} & 1 & $z$ & $90^{\circ}$ & 12.5 & 16.0 & 1.60 \\
\hline & 2 & $y$ & $90^{\circ}$ & 10.5 & 10.0 & 1.15 \\
\hline & 3 & $z$ & $20^{\circ}$ & 33.5 & 12.0 & 3.40 \\
\hline & 4 & $y$ & $120^{\circ}$ & 21.5 & 10.5 & 1.85 \\
\hline & 5 & $z$ & $75^{\circ}$ & 21.5 & 9.5 & 1.70 \\
\hline & 6 & $y$ & $90^{\circ}$ & 23.5 & 5.0 & 0.45 \\
\hline \multirow{6}{*}{ left leg $\boldsymbol{L}_{\mathbf{3}}$} & 1 & $z$ & $85^{\circ}$ & 11.5 & 19.0 & 2.70 \\
\hline & 2 & $y$ & $90^{\circ}$ & 14.5 & 10.5 & 1.35 \\
\hline & 3 & $z$ & $25^{\circ}$ & 37.5 & 13.0 & 5.50 \\
\hline & 4 & $y$ & $120^{\circ}$ & 22.5 & 10.5 & 2.40 \\
\hline & 5 & $z$ & $80^{\circ}$ & 26.0 & 9.5 & 2.05 \\
\hline & 6 & $y$ & $90^{\circ}$ & 23.5 & 6.0 & 0.50 \\
\hline \multirow{6}{*}{ left leg $\boldsymbol{L}_{2}$} & 1 & $z$ & $90^{\circ}$ & 13.0 & 17.0 & 3.40 \\
\hline & 2 & $y$ & $100^{\circ}$ & 14.5 & 10.5 & 1.25 \\
\hline & 3 & $z$ & $25^{\circ}$ & 44.5 & 13.5 & 6.05 \\
\hline & 4 & $y$ & $120^{\circ}$ & 25.0 & 13.5 & 2.60 \\
\hline & 5 & $z$ & $80^{\circ}$ & 27.5 & 10.0 & 3.40 \\
\hline & 6 & $y$ & $90^{\circ}$ & 30.0 & 6.0 & 0.45 \\
\hline \multirow{6}{*}{ left leg $\boldsymbol{L}_{\mathbf{1}}$} & 1 & $z$ & $90^{\circ}$ & 12.0 & 17.0 & 3.75 \\
\hline & 2 & $y$ & $90^{\circ}$ & 12.0 & 11.5 & 1.30 \\
\hline & 3 & $z$ & $20^{\circ}$ & 47.5 & 14.0 & 7.45 \\
\hline & 4 & $y$ & $115^{\circ}$ & 28.0 & 12.0 & 3.50 \\
\hline & 5 & $z$ & $65^{\circ}$ & 33.5 & 10.0 & 3.25 \\
\hline & 6 & $y$ & $90^{\circ}$ & 31.0 & 6.5 & 0.75 \\
\hline
\end{tabular}



Fig. 5 Filming a spider crab in an ELA aquarium 
A chronogram is a schedule displaying on a chart, for each operation, the amount of time it takes, and with all operations arranged in series according to their occurrence.

Videos made by filming live crabs in an ELA aquarium (see Fig. 5), were used to make the chronograms of the crabs locomotion.

Fig. 6 presents a chronogram depicting the locomotion of the spider crab sideways. The white parts of the chronogram represent the leg support phase (the periods of time when a leg is on the ground); the shaded ones represent the leg transfer phase (the periods of time when the legs make movements in the air).

The chronogram presented in Fig. 7 was made using the same video, where the crab was moving sideways. The change of colors in this chronogram allows an easy interpretation of the movement of the legs during a time interval of one second. During the locomotion, the spider crab moves $15 \mathrm{~cm}$ in 4 seconds, meaning that the average speed of the crab in the aquarium is about $3.75 \mathrm{~cm} / \mathrm{s}$.

Fig. 8 shows the trajectory of the left leg $\left(L_{3}\right)$ during a complete locomotion period (transfer phase plus support phase). First, the crab moves the leg up by rotating the "hip" joint; after this, starts the movement of the "knee" joint and, finally, using the "hip" joint, the crab moves the leg down and puts the "foot" on the ground. After these movements, the leg pushes the body and the crab 'moves' the body sideways.

\begin{tabular}{|l|l|l|l|l|l|l|l|l|}
\hline & 1 sec & 2sec & 3sec & 4sec & 5sec & 6sec & 7 sec & 8 sec \\
\hline$L_{1}$ & & & & & & & & \\
\hline$L_{2}$ & & & & & & & & \\
\hline$L_{3}$ & & & & & & & & \\
\hline$L_{4}$ & & & & & & & & \\
\hline$R_{1}$ & & & & & & & & \\
\hline$R_{2}$ & & & & & & & & \\
\hline$R_{3}$ & & & & & & & & \\
\hline$R_{4}$ & & & & & & & & \\
\hline
\end{tabular}

Fig. 6 Chronogram of a spider crab gait

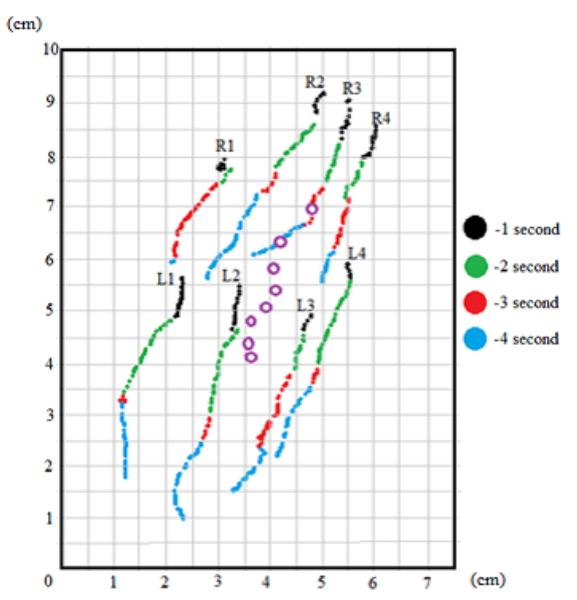

Fig. 7 Chronogram of Maja brachydactyla walking (scale 1:5) 


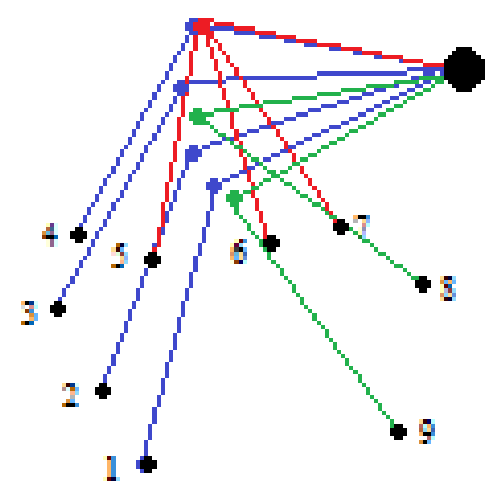

Fig. 8 Trajectory of the crabs' $L_{3}$ leg during one period of locomotion

From the motion analysis, crab crawls along the terrain using four pairs of legs. Crab bends and unbends its legs consistently; the same pair of left and right legs never operates simultaneously. The leg consists of a series of movable articulated elements, whose mass is reduced towards the distal end. All joints allow movements around the $z$ and $y$ axis; this leads to leg flexion and rotation in plane. While walking the center of gravity of the crab is moving almost horizontally.

\section{Kinematic model}

Most walking robots are complex electromechanical systems, displaying variable structures and different number of legs. The available options for robots with legs are enormous, with configurations varying among, for example, 2 legs (biped), 4 legs (quadruped), 6 legs (hexapod) and 8 legs (octopod) like spider crabs. In the sequel a description of the kinematic modeling of an octopod spider crab, is presented.

\subsection{Number of degrees of freedom}

The number of degrees of freedom in a mechanical system is the number of independent parameters defining the position of all elements of the system. Fig. 9 presents the equivalent mechanism of a spider crab leg (simple kinematic scheme), presenting 6 degrees of freedom.

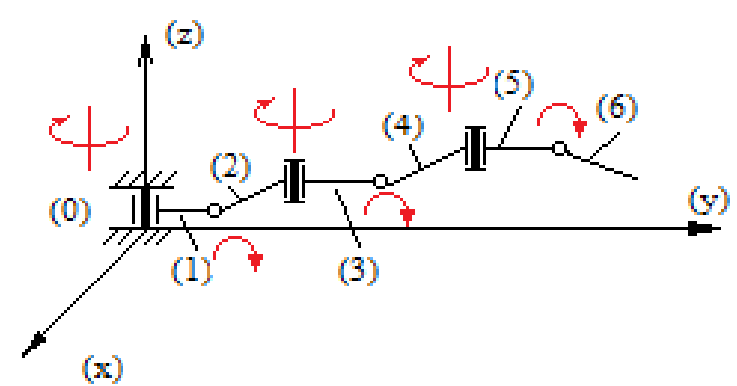

Fig. 9 Equivalent mechanism of a spider crab single leg 


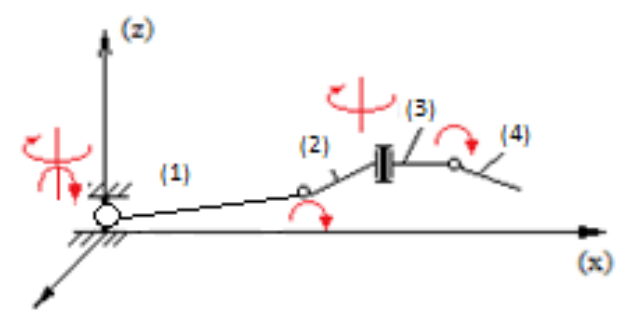

(y)

Fig. 10 Kinematic scheme of a spider crab single leg (simplified mechanism)

Spider crab legs have 6 rotational joints, which allow rotational movements about the $z$ and $x$ axis. In the course of this work, the kinematic scheme of the legs has been changed. First and second segments from each leg were combined into one. This was due to the fact that the first and second leg segments were too small $(\approx 12 \mathrm{~mm})$ and presented a small range of motion $\left(\approx 20^{\circ}\right)$. Thus, it would be difficult to implement this in the real model. However, it was verified that these changes would not have a significant impact on crab's locomotion. The masses and lengths of the remaining segments were not changed, and real data was used.

Fig. 10 shows the new (simplified) kinematic model for the crab's leg. In this case, the leg presents 5 degrees of freedom.

\subsection{SimMechanics kinematic model}

SimMechanics is a library package (toolbox) of Simulink, running on the MATLAB environment, designed to simulate the mechanical motion of solids. Its main purpose is to model the spatial movements of solid-state machines in the engineering design stage, using the laws of theoretical mechanics (Mathworks 2014).

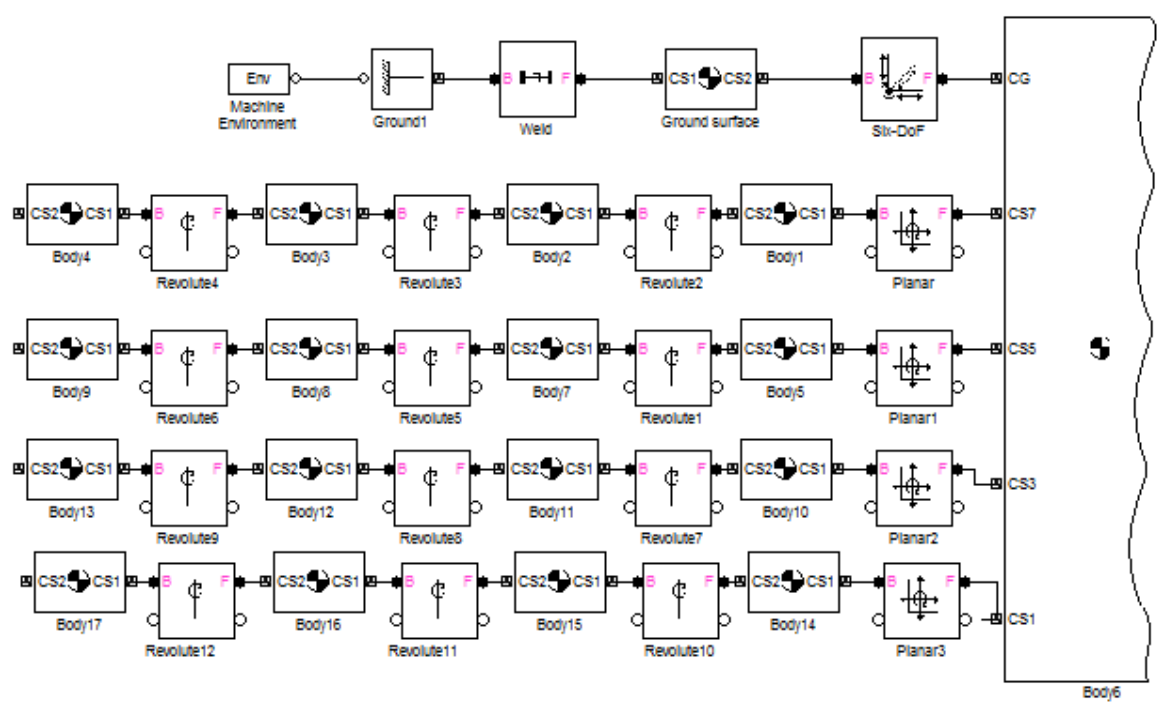

Fig. 11 The kinematic model of the crab 




Fig. 12 SolidWorks model of the crab

All limbs of the crab were modeled, and connected to the body model, through rotational joints, as represented in Fig. 11. The model presents a simple kinematic diagram, without sensors, actuators, and control system.

\subsection{SolidWorks model}

SolidWorks (Dassault Systemes 2014) was used to model the geometry of the Spider crab, namely to draw all single parts of the crab's body, and later connect all parts in one model (see Fig. 12). This model was made using original data and has dimensions equal to the real size of the crab measured in ELA.

\section{Dynamic model}

In order to make a dynamic simulation of the crabs' locomotion, the SimMechanics toolbox of Matlab/Simulink was used. The dynamic model is based on the kinematic model and on the real measurements of the spider crabs. This means that the variables length, radius and mass of the legs and body of the robot are parametrically programmed in the dynamic model.

\subsection{SimMechanics dynamic model}

The Robot Kinematic block model (see Fig. 13) is based on the kinematic model implemented in SimMechanics. Here the grey Body block represents the body of the crab, the eight blue subsystems represent the legs, and the eight small green subsystems are ground contact blocks. The ground is fixed at $z=0$ and the position of the robot's center of gravity is connected through a 6 DOF block to the ground.

Each leg has the same structure and their dynamic model is presented on Fig. 14. Blue (side shaded) blocks are Body blocks (representing links), and green (outline shaded) blocks are rotational joints, with joint sensors and actuators. There is also a Proportional $(\mathrm{P})$ controller for each joint (although the Simulink block used is a PID, only the proportional term is used in this case). 


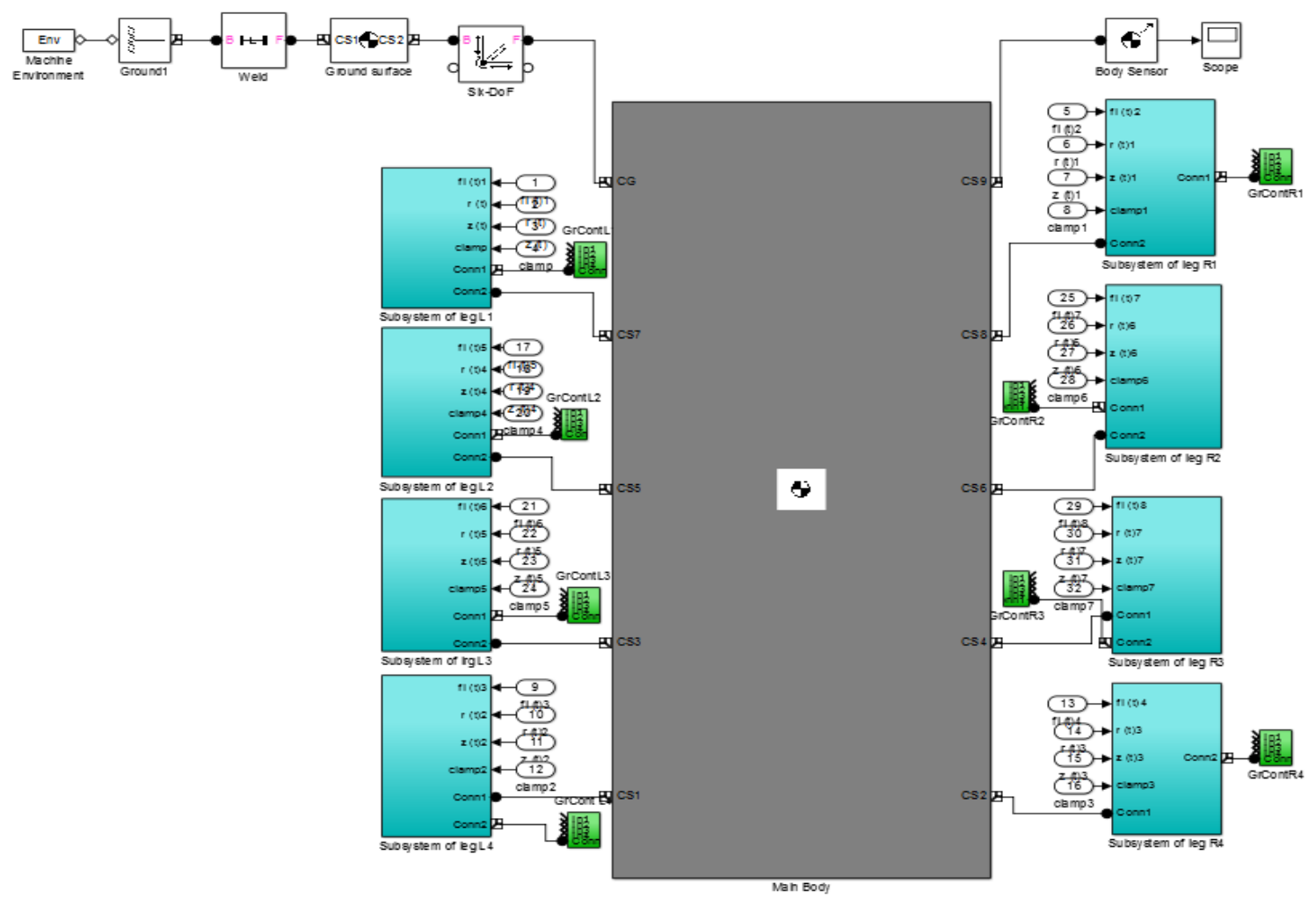

Fig. 13 SimMechanics representation of the crab

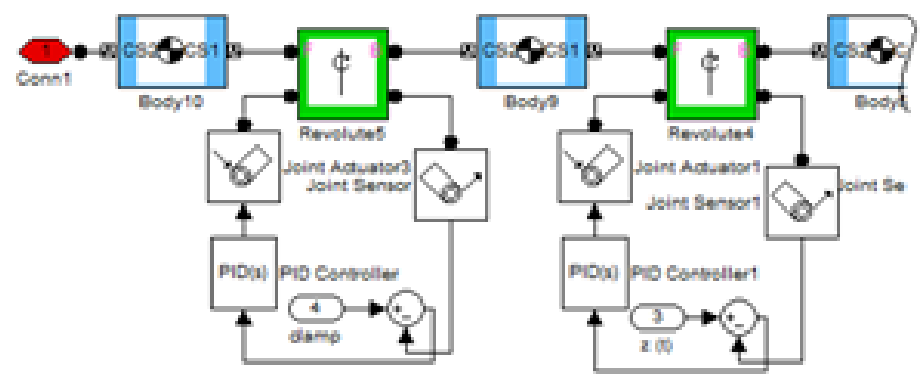

Fig. 14 Detail of the dynamic model of a crab's leg in SimMechanics

\subsection{Ground contact}

The coordinate system in the simulator, at $t=0$, is directly linked to the neutral point in the frame $(0,0,0)$, meaning that the robot starts with a preset body height directly centered above the zero frame point. The legs of the robot are connected to the body frame and to the robot's coordinate system. On the contrary, the feet of the robot are observed in the world coordinate system to determine the world $z$. If $z \leq 0$ it means that there is a contact with the ground and the forces of the ground should be reflected to the feet as a Ground Reaction Force (GRF), as shown in Fig. 15. 


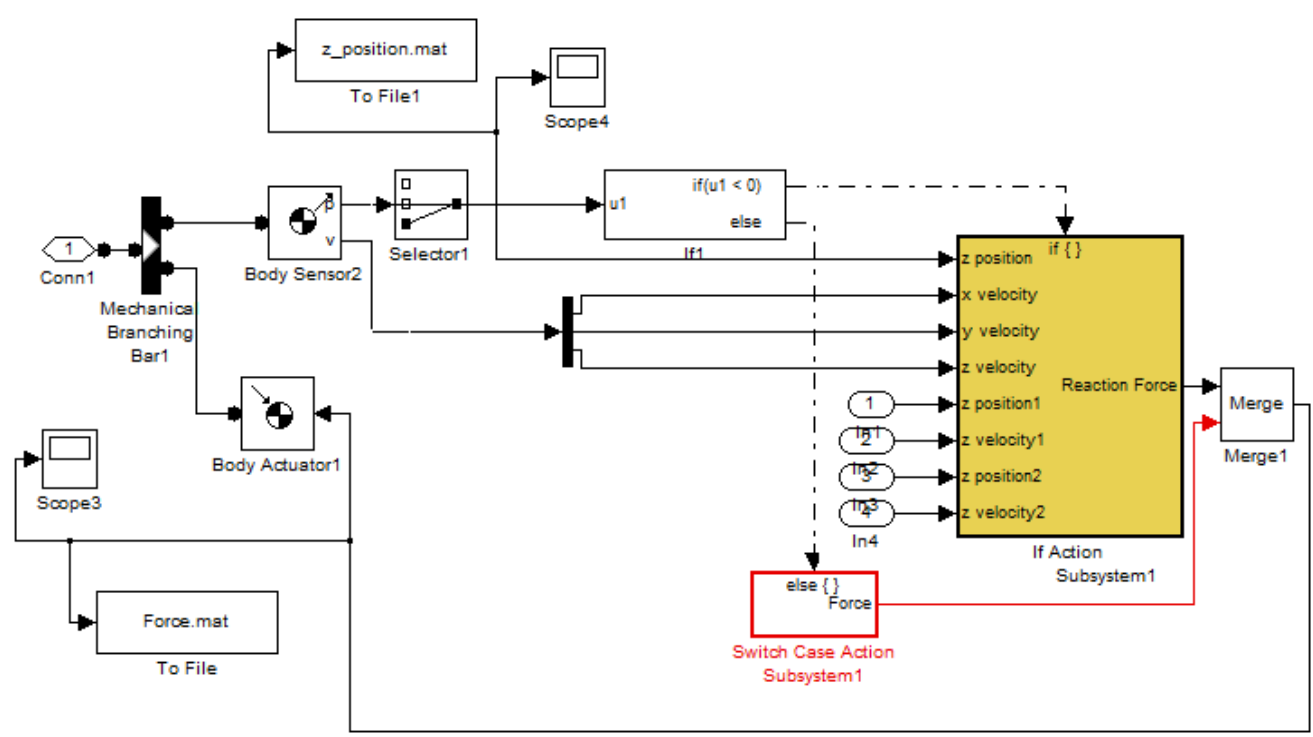

Fig. 15 SimMechanics implementation of the ground contact model, which determines if the leg is on the ground or in the air, and the corresponding contact force

In order to let the robot walk in a given direction, friction coefficient $(\mu=0.1)$ has to be introduced when the foot touches the ground, according to Eq. (1)

$$
\begin{gathered}
F_{n}=\left\{\begin{array}{cc}
-z \cdot K_{\text {contact }} \dot{z} \cdot D_{\text {contact }}, & \text { if } z \leq 0 \\
0 & \text { otherwise }
\end{array}\right. \\
F_{w x}=\left\{\begin{array}{cc}
-\left[\left(\frac{2}{1+e^{-10 \dot{x}}}\right) \cdot \mu \cdot F_{n}\right], & \text { if } z \leq 0
\end{array}\right. \\
F_{w y}=\left\{\begin{array}{cc}
-\left[\left(\frac{2}{1+e^{-10 \dot{y}}}\right) \cdot \mu \cdot F_{n}\right], & \text { otherwise } \\
0 & \text { if } z \leq 0
\end{array}\right.
\end{gathered}
$$

Basically $F_{w}=V \mu F_{n}$, with $F_{n}=-z \cdot K_{\text {contact }}-\dot{z} \cdot D_{\text {contact }}$ being $V$ a Sigmoid step function $2 /\left(1+e^{-10 \dot{x}}\right)$, depending of the contact speed but with a $(0,0)$ crossing.

\subsection{Trajectory planning of the crab in Simulink}

The structure of the legs trajectory planning subsystem is presented in Fig. 16. The input signals (except for control signals) are combined through a multiplexer and fed to the input subsystem functional analysis, of the mismatch of the current and terminal coordinates. The control signal is supplied to the comparison unit, which analyses the enabling or disabling of the sensor interrogation procedures. If the signal is equal to +1 , the job passes to the next subsystem. If the signal is zero, then no change occurs in the system. The main outputs are: the rotation speed of 


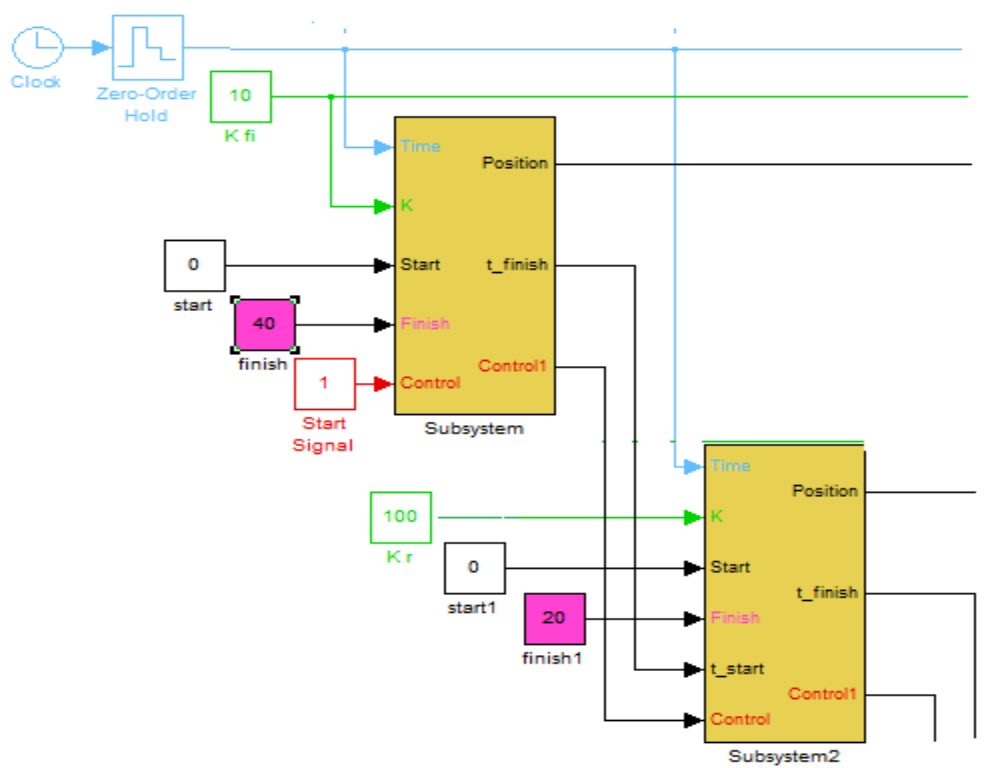

Fig. 16 The integrated simulation model of the motion planning of the start point

the working body (leg), start time of motion, terminal point of the movement of the working body and control signal.

This subsystem was validated by connecting it to the SimMechanics robot model. Simulation results are presented in the next section.

\section{Model simulation and results}

To analyze the simulation results of different dynamic systems, one of the best methods is to perform the visualization, or animation, of the model while the simulation is running. This section presents the results of several simulation tests performed on the developed model.

\subsection{Simulation with one leg}

The first test of the mechanism model was made considering that the robot would have only one leg (see Fig. 17), to check the correctness of the ground contact model.

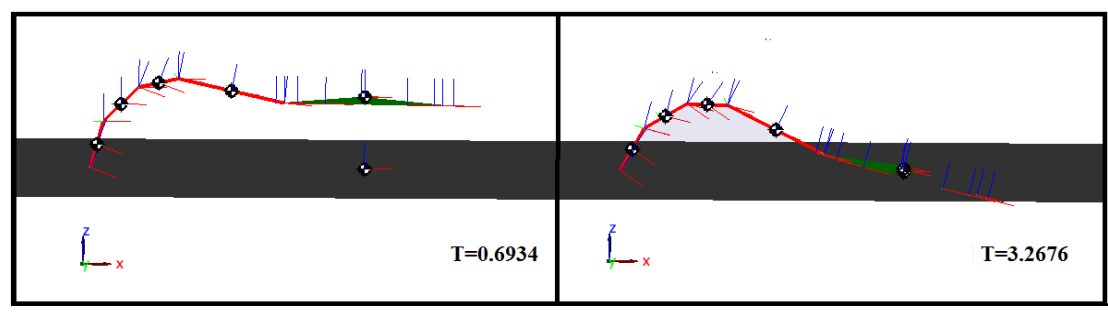

Fig. 17 Simulation of the crab with one leg 
Ground reaction force acting on the leg makes the body move and fall down on the surface, while keeping the distal part of the leg steady on place, meaning that the ground contact model is working correctly.

The plots depicted in Fig. 18 show the movement of the body in the $x, y$ and $z$ axis (a "Scope" was connected to the body center of gravity $(\mathrm{CG})$ ). $z$ position (red line) shows that the body actuated by the gravity force, moves from the position $50 \mathrm{~mm}$ and falls down crossing the ground.

\subsection{Simulation of the Spider Crab Locomotion}

Fig. 19 presents a plot of the spider crab model displacement in the $x y$ plane during a 50 seconds simulation.

The crab's model has eight legs, positioned in relation to the body according to a real spider crab, being four on the left side and four on the right side. To obtain this plot, a "Scope" was connected to the CG of the crab's body, with initial position at $(0,84,50)$. Dash-dotted line displays the crab's displacement during the simulation along $x$ - axis, which was the crab's moving direction set for this simulation. The first 5 seconds of the simulation correspond to a transient phase, where the crab is starting to move from a stand-still position to a walking mode. The crab walks forward during 40 seconds and then it starts to return back.
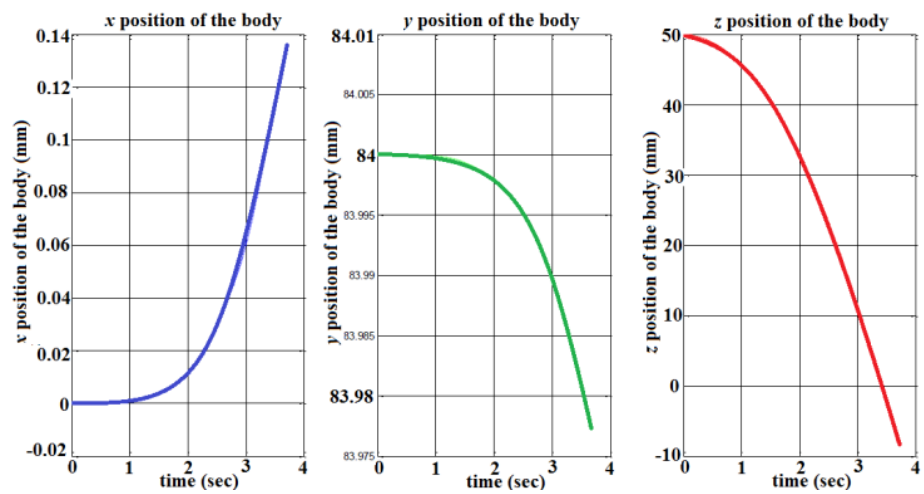

Fig. 18 Plots of the $x, y$ and $z$ positions of the crab's body during simulation with just one leg

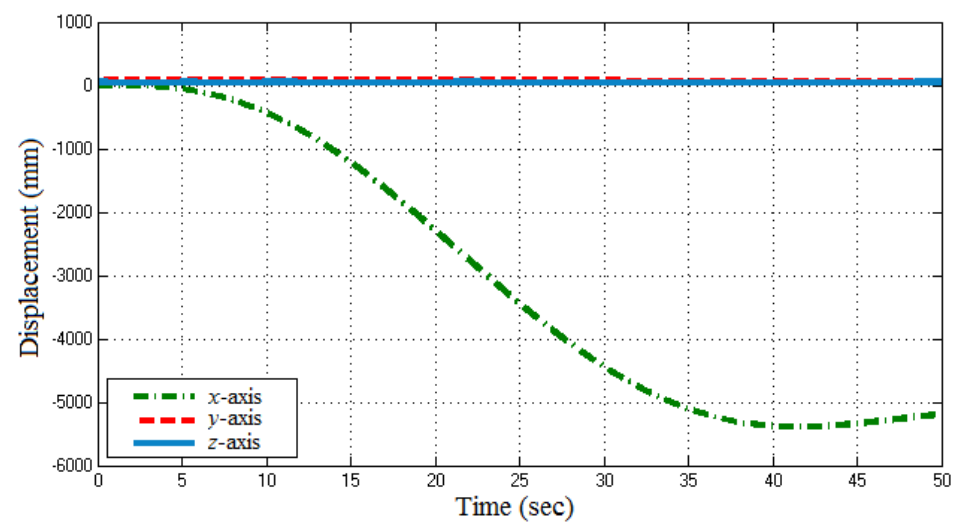

Fig. 19 Displacement of the crab's body during simulation $(0-50 \mathrm{sec})$ 
To check the accuracy of the plot above (Fig. 19) were made screenshots of the spider crab model locomotion during the 50 seconds simulation interval (depicted in Fig. 20). The picture shows the displacement of the body, relatively to the surface and CG of the ground $(0,0,0)$ coordinates. The locomotion of the model observed in Fig. 20 corresponds to the displacement plot presented in Fig. 19.

For more detailed visualization of the spider crab locomotion and motion of its legs, screenshots were made for a simulation interval of 8 seconds (see Fig. 21). In this figure, it is possible to see that the CG of the body moves against the CG of the ground. Fig. 22 presents the plot of the crab's body position during this 8 seconds simulation.

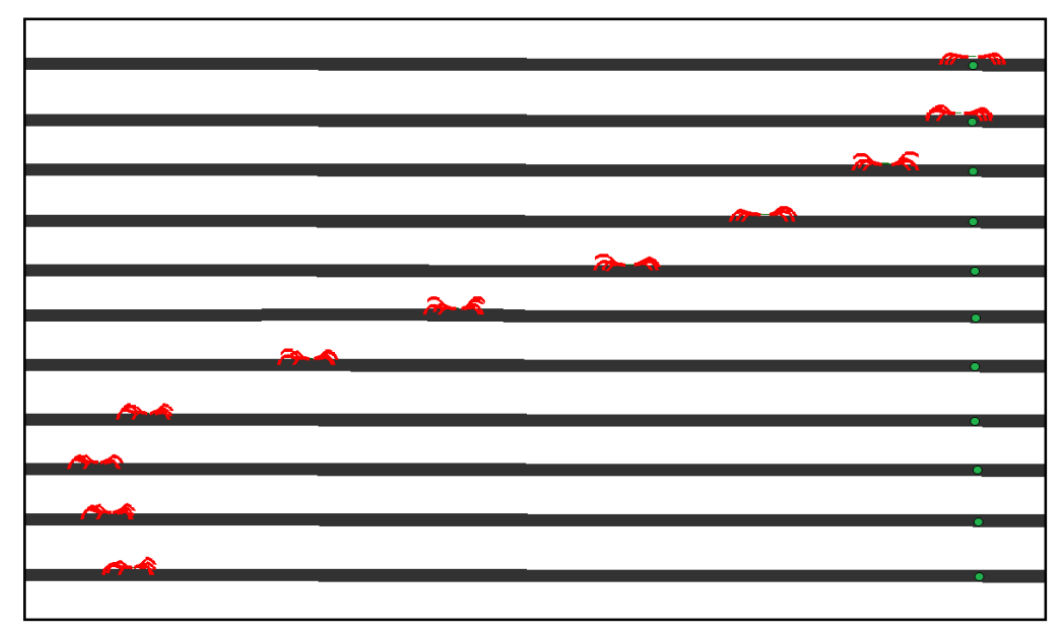

Fig. 20 Simulation screenshots of the spider crab $(0-50 \mathrm{sec})$

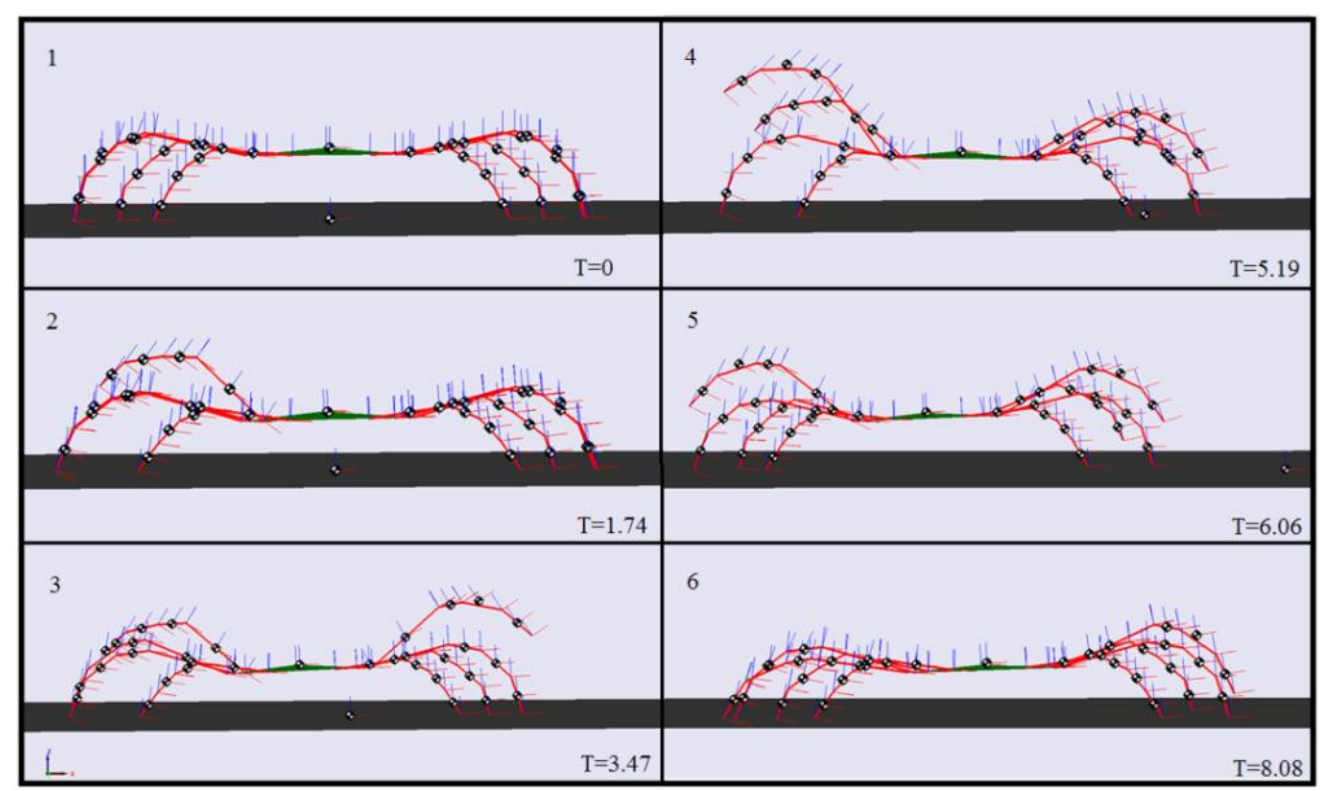

Fig. 21 Simulation of the spider crab $(0-8 \mathrm{sec})$ 


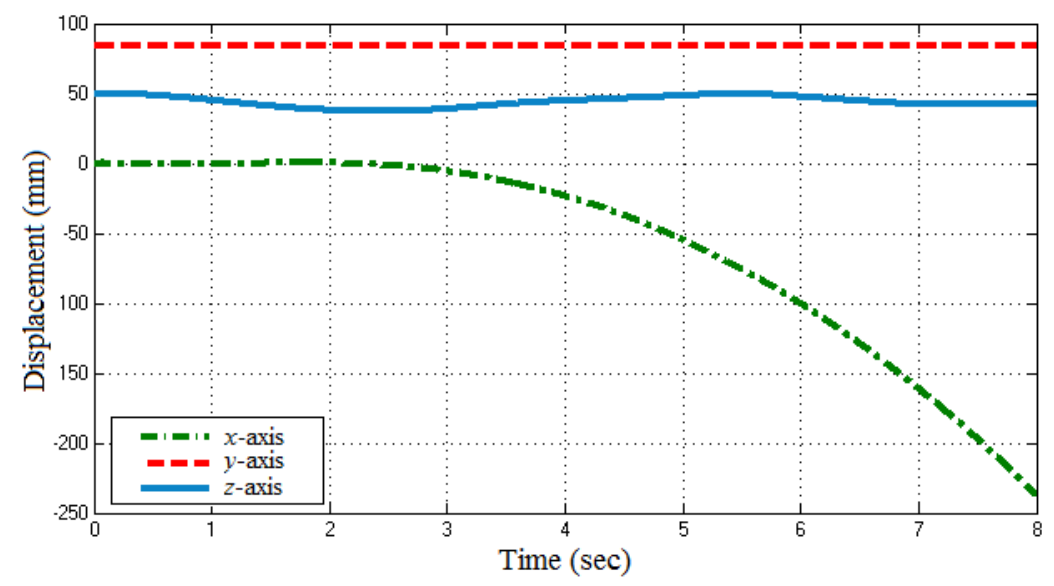

Fig. 22 Displacement of the crab's body during simulation

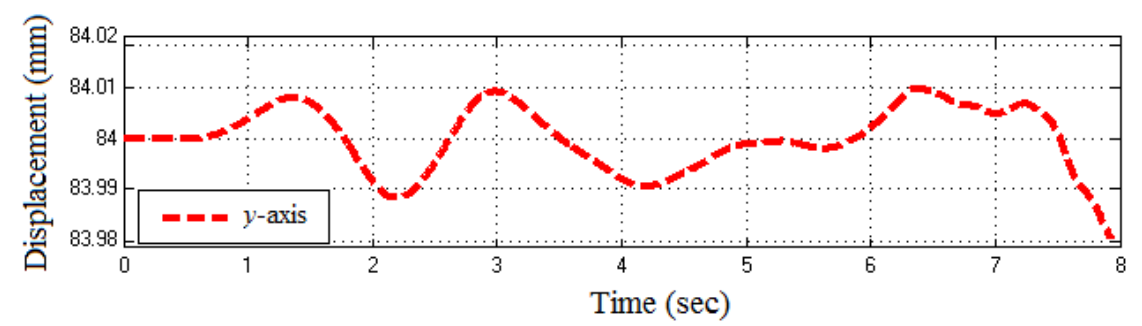

Fig. 23 Displacement of the crab's body along the $y$-axis during simulation $(0-8 \mathrm{sec})$

Dash-dotted line displays the crab's displacement along $x$-axis during the simulation. As can be seen from the chronograms made while studying the locomotion of the crab (Fig. 7), during 4 seconds the crab moves $15 \mathrm{~cm}$, meaning that in 8 seconds it should pass $30 \mathrm{~cm}$.

The obtained simulation results are very similar to real ones. The simulated crab model starts to move from a standstill position to a walking mode, moving $24 \mathrm{~cm}$ in 8 seconds.

The solid line in the plot is the displacement along the $z$-axis; as can be seen from the plot, the line is wavy, showing that the CG of the body goes up and down during the simulation, because as the crab raises the legs, the body weight increases, thus increasing the pressure on the supporting legs; this makes the crab stabilize its position and balances.

The dotted line represents the displacement along the $y$-axis. On the chart, this line seems straight because of the large chart scale that prevents to see the small displacements. But by zooming the image (Fig. 23), it can be seen that the CG of the body also varies along the $y$ direction.

Fig. 24 depicts a group of charts representing the reaction force and the $z$ position for each distal part of the leg on the crab's left side, during the simulation. As can be seen from the graphics, the legs move and when the $z$ position comes to 0 the reaction forces of the ground act on the distal part of the leg. Legs $L_{2}$ and $L_{3}$ have amplitude of motion larger than $L_{1}$ and $L_{4}$ - these legs are the main responsible for the crab locomotion (Fig. 6). The reaction forces depend on the legs movement amplitude and speed, and that is why they are bigger for the legs $L_{2}$ and $L_{3}$.

Similarly, Fig. 25 represents a group of charts of the reaction force and $z$ position of each right 


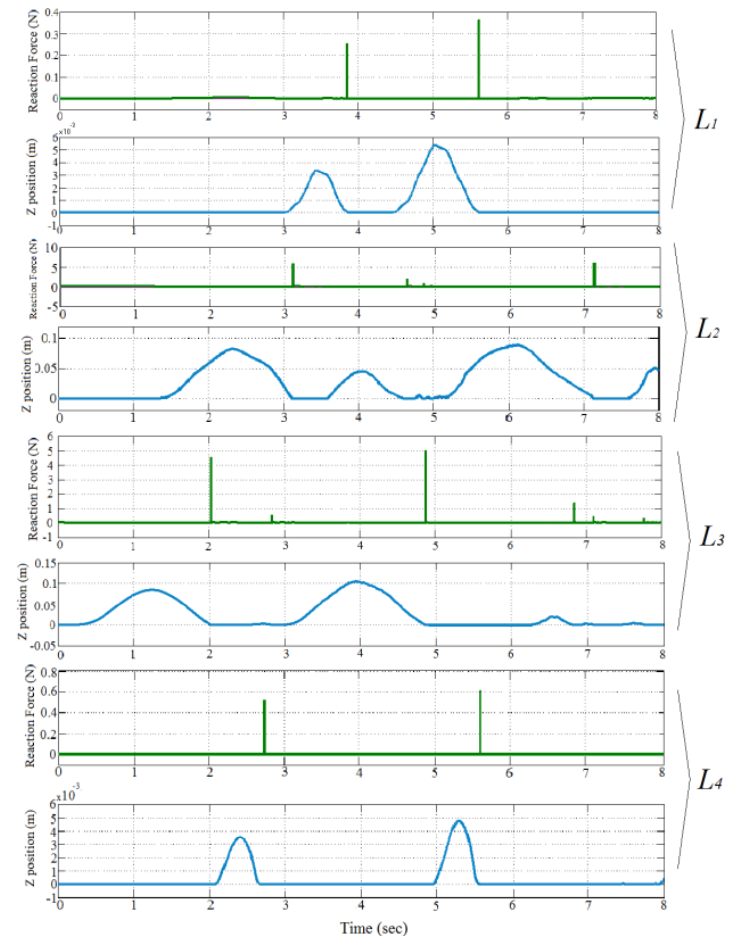

Fig. 24 Plot of reaction force and $z$ position of the left legs distal part during simulation

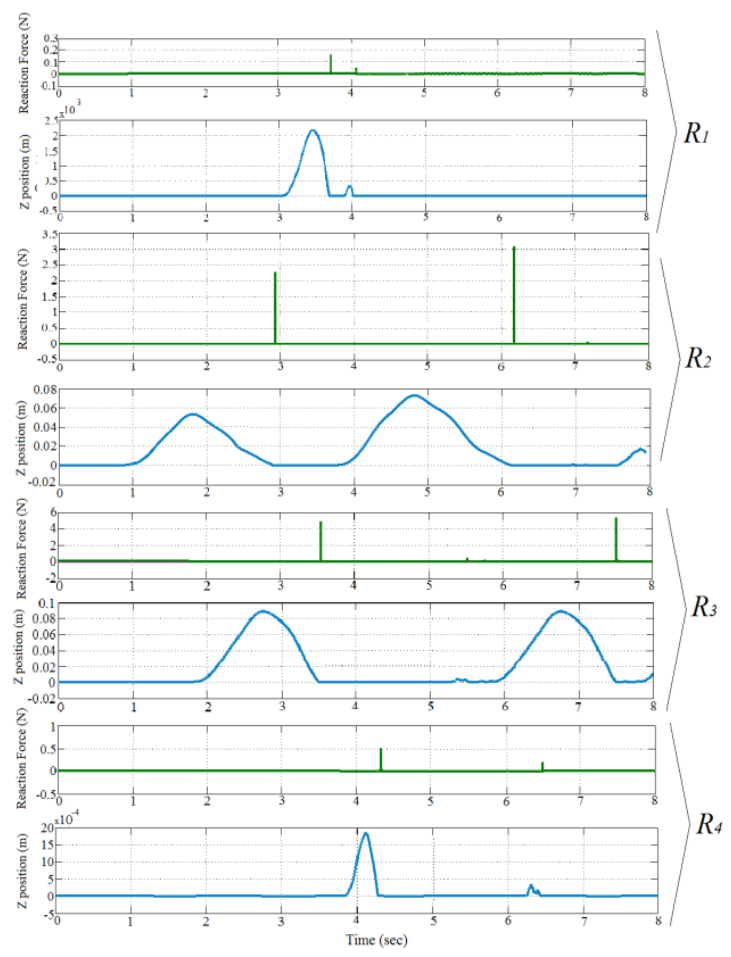

Fig. 25 Plot of reaction force and z position of the right legs distal part during simulation 


\begin{tabular}{|l|l|l|l|l|l|l|l|l|}
\hline & 1 sec & 2 sec & 3 sec & 4 sec & 5 sec & 6 sec & 7 sec & 8 sec \\
\hline$L_{1}$ & & & & & & & & \\
\hline$L_{2}$ & & & & & & & & \\
\hline$L_{3}$ & & & & & & & & \\
\hline$L_{4}$ & & & & & & & & \\
\hline$R_{1}$ & & & & & & & & \\
\hline$R_{2}$ & & & & & & & & \\
\hline$R_{3}$ & & & & & & & & \\
\hline$R_{4}$ & & & & & & & & \\
\hline
\end{tabular}

Fig. 26 Chronogram of a spider crab gait, during simulation
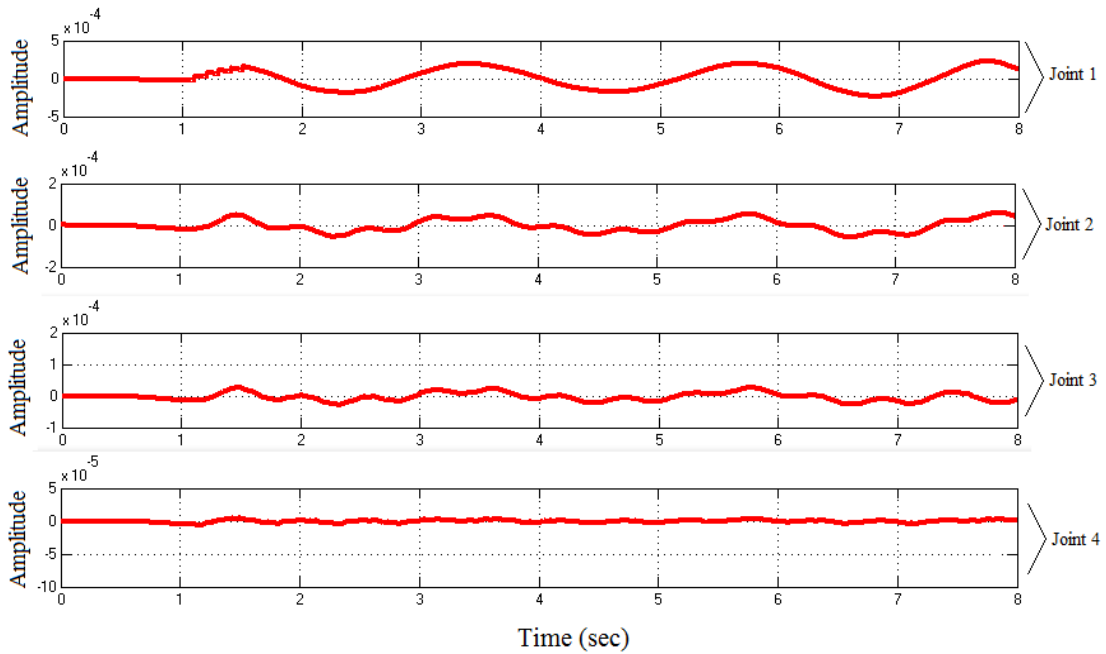

Fig. 27 Proportional controller output, during the simulation (representation of all joints of the leg $L_{2}$ )

side legs distal part, during the simulation. Just as with the left legs, on the right side the main legs for implementing the locomotion are $R_{2}$ and $R_{3}$, and the reaction forces of these legs are bigger. The crab also moves legs $R_{1}$ and $R_{4}$, as well as $L_{1}$ and $L_{4}$, but uses them mainly for the body equilibrium and stability.

Regarding the control of the model during walking, the controller attempts to minimize the error by adjusting the process control inputs. For the spider crab simulation was used a Proportional $(\mathrm{P})$ controller that produces an output value that is proportional to the current error value. The plots on Fig. 27 represent the $\mathrm{P}$ controller output signal amplitudes for each joint of leg $L_{2}$. The proportional term contributes to the bulk of the output change; the control action is responding to the system disturbances and the system becomes stable.

\section{Conclusions}

\subsection{Conclusions}

The main idea behind this work is to gain knowledge of biological beings that evolved over millions 
of years, and apply this knowledge in practice, in robotics design. The final goal of this work it the development of a spider crab biologically inspired robot, with the ability to walk on the shore and in the surf zone, subject to existing currents and ripples, and being able to withstand these ambient conditions, with the purpose of maintaining the location register of pipelines that cross the surf zone, the regular survey of their location, and also their inspection.

In this paper is presented the first phase of this project, whose goal is the modelling and simulation of the spider crab. The strategy is to understand the animal's kinematic and dynamic characteristics as the default in the design and control of a robot model.

In laboratory, the parts of the crab's body were measured, and the locomotion and trajectory of the crab movements were studied, to implement a realistic, and real data-based simulation model. The crab model was implemented and programmed in Matlab/SimMechanics and in SolidWorks. The legs of the crab were individually controlled, but were not equally constructed as for shape, size and mass. In the dynamic environment, gravity and mass are affecting the model. Adopted model parameters (mass, length, diameter, motion amplitudes) are the same as the ones of the real crab. The kinematic model has been slightly changed, to make a less complex model, without significantly changing the biomechanical properties of the Spider Crab. The dynamic model included a ground contact model implemented in order to make the robot stand on the ground surface. This model was implemented by considering the feet ground reaction force, and a discrete-positional joint trajectory planning system was used to make the robot move in the desired direction. Closer attention was given to the spider crab's biology and biomechanical aspects in the design of this robot model. Concerning the locomotion, the algorithm presented in this paper allows the crab to walk sideways. As a result, a robot model that is moving in an "animal like" manner was obtained.

\subsection{Perspectives for Future Developments}

To further develop the simulation model described in this paper towards a realistic spider crab model, the following development steps are needed:

- Design an algorithm for the general path planner in order to make the robot walk according to a desired trajectory;

- In the future it is necessary for the robot to climb rocks, to walk on sand surfaces, and to enter to the water, as a real spider crab does. These extra features will reduce the stability of the robot, so it is necessary to investigate dynamic stability algorithms;

- The development of a real robot biologically inspired in "Maja brachydactyla", is the final objective for future work.

\section{Acknowledgements}

This work is funded (or part-funded) by the ERDF - European Regional Development Fund through the COMPETE Programme (operational programme for competitiveness) and by National Funds through the FCT - Fundação para a Ciência e a Tecnologia (Portuguese Foundation for Science and Technology) within project "FCOMP - 01-0124-FEDER-022701".

Thanks to ELA and Prof. Mike Weber for permission to use the laboratory, material and tools to studying crabs, and for allowing filming and photographing the crabs inside the aquarium. 


\section{References}

Asif, U. and Iqbal, J. (2010), "Design and simulation of a biologically inspired hexapod robot using simmechanics", Proceedings of the Robotics Conference (Robo'2010), Phuket, Thailand.

Ayers, J. and Witting, J. (2000), "Biomimetic approaches to the control of underwater walking machines", Philosophic. Trans. Roy. Soc., 365(1850), 273-295.

Birch, M., Quinn, R., Hahm, G., Phillips, S., Drennan, B., Fife, A., Verma, H. and Beer, R. (2000), "Design of a cricket microrobot", Proceedings of the IEEE International Conference on Rob. \& Aut. (ICRA'2000), San Francisco, CA.

Cbor pipe inspection rov (2014), Available: http://steadyflux.com/products/cbor/.

Dan Stan, S. (2008), "Kinematics analysis, design, and control of an isoglide3 parallel robot (ig3pr)", Industrial Electronics, IECON 2008, 34th Annual Conference of IEEE.

Dassault Systemes (2014), "Solidworks", Available: http://www.solidworks.com/.

Davis, S., Tresadern, P., Canderle, J., Tsagarakis, N.G., Dodd, P. and Caldwell, D.G. (2003), "The biomimetic design of "soft" mechatronic systems", Proceedings of the 11th IEEE International Conference on Advanced Robotics (ICAR'2003), Coimbra, Portugal.

Dede, M.I.C. and Tosunoglu, S. (2006), "Virtual rapid robot prototyping”, Early Career Tech. J., ASME, 5(1), 7-1.

Dudek, G., Giguere, P., Prahacs, C., Saunderson, S., Sattar, J., Torres-Mendez, L., Jenkin, M., German, A., Hogue, A., Ripsman, A., Zacher, J., Milios, J., Liu, H., Zhang, P., Buehler, M. and Georgiades, C. (2007), "Aqua: An amphibious autonomous robot", IEEE Comput. Magaz., 40(1), 46-53.

Fukuda, T., Hasegawa, Y., Sekiyama, K. and Tadayoshi, A. (2012), Multi-Locomotion Robotic Systems: New Concepts of Bio-inspired Robotics, volume 81 of STAR - Springer Tracks in Advanced Robotics, Springer, Berlin, Germany.

Hennion, B., Pill, J. and Guinot, J.C. (2005), "A biologically inspired model for quadruped locomotion", Proceedings of the 8th International Conference on Climbing and Walking Robots, (CLAWAR'2005), London, U.K.

Nesnas, I.A.D., Matthews, J.B., Abad-Manterola, P., Burdick, J.W., Edlund, J.A., Morrison, J.C., Peters, R.D., Tanner, M.M., Miyake, R.N., Solish, B.S. and Anderson, R.C. (2012), "Axel and duaxel rovers for the sustainable exploration of extreme terrains", J. Field Robot., 29(4), 663-685.

Kevin, C., Galloway, G.C., Haynes, B., Ilhan, D., Aaron, M.J., Knopf, R., Lynch, G., Plotnick, B., White, M. and Koditschek, D.E. (2010), "X-rhex: A highly mobile hexapedal robot for sensorimotor tasks", Technical report, University of Pennsylvania.

Lepora, N., Verschure, P. and Prescott, T. (2013), "The state of the art in biomimetics", Bioinspir. Biomimet., 8(1), 013001.

Lutz, P.L., Musick, J.A. and Wyneken, J. (2002), The Biology of Sea Turtles, Volume II, CRC Marine Biology Series, CRC Press, Boca Raton, Florida, USA, ISBN: 978-142-004080-7.

Mathworks (2014), "Simmechanics", Available: http://www.mathworks.com/products/simmechanics/.

Mederreg, L., Hugel, V., Bonnin, P., Blazevic, P., Abourachid, A. and Stasse, O. (2003), "The robocoq project modeling and design of bird-like robot equipped with stabilized vision", Proceedings of the 6th International Conference on Climbing and Walking Robots, (CLAWAR'2003), Catania, Italy.

Peng, S., Lam, C.P. and Cole, G.R. (2003), “A biologically inspired four legged walking robot”, Proceedings of the IEEE International Conference on Rob. \& Aut. (ICRA'2003), Taipei, Taiwan.

Shaoqiang, Y., Zhong, L. and Xingshan, L. (2008), "Modeling and simulation of robot based on matlab/simmechanics", In Control Conference, CCC 2008, 27th Chinese, IEEE.

Shuster, C.N. (1982), "A pictorial review of the natural history and ecology of the horseshoe crab Limulus polyphemus, with reference to other Limulidae", Progress in clinical and biological research, 81, 1-52.

Sutoh, M., Yusa, J., Ito, T., Nagatani, K. and Yoshida, K. (2012), "Traveling performance evaluation of planetary rovers on loose soil", J. Field Robot., 29(4), 648-662.

The european spider crab biology and fishery (2014), Available: http://www2.hawaii.edu/ carlm/spider.html. 
World register of marine species - maja squinado (herbst, 1788) (2014), Available: http://www.marinespecies.org/aphia.php?p=taxdetails\&id=107350.

Xiaodong, Z. and Shusheng, B. (2012), “A survey of bioinspired compliant legged robot designs”, Bioinspir. Biomimet., 7(4), 041001.

CC 